\title{
TEATRO DE BONECOS E A ANIMAÇÃO À VISTA DO PÚBLICO. ${ }^{1,2}$
}

\author{
Valmor Beltrame ${ }^{3}$ \\ Alex de Souza ${ }^{4}$
}

\begin{abstract}
RESUMO: A animação de bonecos à vista do público é uma linguagem que compõe o teatro de animação e cada vez mais se percebe a sua utilização. Enquanto recurso cênico, encontra-se a sua recorrência desde o Japão no século XVIII, mas principalmente após a segunda metade do século XX a animação de bonecos à vista do público vem se disseminando e desenvolvendo, ganhando características que a destacam como linguagem e provocam transformações na poética do teatro de animação.
\end{abstract}

PALAVRAS-CHAVE: Teatro de Bonecos; Transformações no Teatro de Animação; Animação à vista do público; Características da linguagem.

Uma característica interessante do nosso teatro de animação contemporâneo é, sem dúvida, a diversidade e o hibridismo das linguagens que o compõe. Entre as diversas possibilidades de linguagem, uma particularmente interessante e, atualmente muito recorrente, é a animação à vista do público. Trato aqui a animação à vista do público como sendo uma linguagem, considerando que esta escolha exige uma concepção de espetáculo diferenciada, assim como a dramaturgia, a confecção dos bonecos, a iluminação, o espaço cênico, a preparação do animador e, conseqüentemente, a relação com o público.

Além dos aspectos que determinam as especificidades desta linguagem, é importante considerar o desenvolvimento da animação à vista, pois ele está intrinsecamente relacionado com a construção histórica do teatro de animação contemporâneo. E é por este último viés que se pretende encaminhar o presente artigo.

\footnotetext{
${ }^{1}$ Trabalho oriundo da Pesquisa "Teatro de Bonecos: transformações na poética da linguagem”, CEART/UDESC.

${ }^{2}$ Este artigo, com algumas modificações, foi publicado no livro "Teatro de Bonecos: Distintos olhares sobre teoria e prática", Udesc, 2008.

${ }^{3}$ Orientador da Pesquisa, professor do Departamento de Artes Cênicas, CEART/UDESC.

${ }^{4}$ Graduado em Lic. Ed. Artística: Hab. Artes Cênicas, vinculado ao Projeto de Pesquisa como Voluntário.
} 


\section{Influências do oriente}

Possivelmente uma das maiores influências no recorrente uso da animação à vista do público vem do Bunraku. Esta arte teatral japonesa, composta por três distintas partes - a narração épica, a música instrumental e a animação de bonecos - que se complementam, possui algumas peculiaridades no que se refere à animação dos bonecos.

Até o início do século XVIII, as representações do ningyô jôruri ${ }^{5}$ eram feitas de forma que os animadores ficavam ocultos do público e havia um animador para cada boneco. Eles somente começam a ganhar visibilidade perante o público, tal como conhecemos hoje, a partir de 1705 , atendendo ao apelo visual dos espectadores que desejavam conhecer os habilidosos artistas (KUSANO, 1993).

Cerca de trinta anos depois surge outra característica marcante desta arte: a utilização de três animadores em cada um dos bonecos que representam personagens principais da narrativa. Para dar mais realismo e precisão aos movimentos, cada animador é responsável por uma parte do boneco, de acordo com uma hierarquia. $\mathrm{O}$ menos experiente, anima os pés; o de nível intermediário é responsável pela mão esquerda do boneco e o mais graduado anima a cabeça e o braço direito, além de sustentar a maior parte do peso do boneco em seu antebraço esquerdo.

No entanto, para evitar que este grande volume de pessoas atrás do boneco desvie toda a atenção dos espectadores, os animadores vestem-se inteiramente de negro. Desta forma, convenciona-se que eles não existem, apesar de ser visível o contorno dos corpos humanos por trás dos personagens. Quando a cena a ser representada é de difícil execução ou exige uma grande dramaticidade, os três animadores cobrem-se totalmente, incluindo as mãos e a cabeça. Em outras cenas, o animador-chefe deixa à vista seu rosto e usa até mesmo um figurino com cores, mantendo sempre a neutralidade de seu rosto, evitando demonstrar qualquer expressão ou reação.

Na década de 1960, um grupo de artistas japoneses fez uma turnê pela América do Norte, apresentando o Bunraku nos Estados Unidos e no Canadá. Esta arte japonesa já era conhecida no ocidente através dos relatos de viajantes que o tinham assistido no Japão, mas

\footnotetext{
${ }^{5}$ Nome original deste gênero. O nome Bunraku passa a ser um sinônimo mais popular desta arte a partir de 1872, em homenagem ao artista Uemura Bunrakuken (1737-1810), fundador da casa teatral Bunraku-za.
} 
a partir desta primeira turnê ele desperta mais o interesse ocidental, especialmente por parte dos bonequeiros que começam a se apropriar de algumas de suas características, entre elas, a animação à vista do público.

As apropriações ocidentais, em geral, não procuraram reproduzir totalmente o Bunraku, uma vez que as diferenças culturais são muito grandes e uma parte dos signos nem poderia ser compreendido por uma outra cultura. Talvez por isso tenham-se criado, com o passar do tempo, algumas confusões na denominação de técnicas específicas relacionando-as com a arte japonesa que as disseminou.

É freqüente não só os bonequeiros, mas até mesmo literaturas ${ }^{6}$ de teatro de animação definirem a animação direta como sendo uma "técnica Bunraku” ou definirem um espetáculo que utiliza a animação à vista do público como sendo um espetáculo de Bunraku. Para esclarecer, o Bunraku não é somente uma técnica ou um recurso, mas uma arte complexa, composta por uma diversidade de linguagens, técnicas e recursos, dentre estes, a animação de bonecos à vista do público. Mesmo quanto à animação dos bonecos de forma direta, há controvérsias discutíveis, pois os animadores japoneses movimentam as distintas partes do boneco através de extensores e mecanismos.

O único espetáculo que pode ser chamado genuinamente de Bunraku é aquele produzido em Osaka, pela Companhia Bunraku-za, do Teatro Nacional de Bunraku. Os outros, são apropriações de técnicas ou releituras do gênero.

\section{Apropriação européia na metade do século $\mathrm{XX}$}

No início do século XX algumas experiências procuravam renovar o teatro de bonecos europeu, seguindo as vanguardas artísticas. No entanto, as rupturas mais significativas surgiram ao fim da Segunda Guerra Mundial. Neste período de reestruturação social e política de muitas nações, os antigos valores começaram a ser fortemente questionados e o teatro de bonecos clássico, predominante até então, começou a ser também discutido e outras formas foram experimentadas.

Este teatro de bonecos clássico pode ser definido como um teatro homogêneo, onde não há o destaque de outros meios de expressão e todos os elementos da encenação estão à

\footnotetext{
${ }^{6}$ Cf. CURCI, 2007; AMORÓS e PARICIO, 2005.
} 
serviço unicamente do boneco. Em contraponto iniciou-se o desenvolvimento do teatro de bonecos heterogêneo, que busca justamente a multiplicidade de meios expressivos para compor um único trabalho artístico (JURKOWSKI, 2000).

Assim, as outras partes constitutivas da encenação, como o cenário, a música e até mesmo a atuação do bonequeiro, passaram a ter tanto valor em cena quanto o próprio boneco. Já não se buscava mais esconder todos os procedimentos técnicos e criar a total ilusão de que os bonecos possuíam vida própria. A partir desta forma de pensar, surgiram com mais freqüência bonequeiros dividindo a cena com seus bonecos. A recorrência da animação à vista na Europa nesta época gerou inúmeras discussões, dividindo os artistas. Refletindo sobre estes conceitos de teatro de bonecos homogêneo e heterogêneo, JURKOWSKI (2000, p.63) observa:

\begin{abstract}
Esse teatro de bonecos homogêneo não é nada mais do que um teatro de bonecos não contaminado por outros meios de expressão. Ele possui todas as condições para desenvolver seu próprio estilo, sem medo de perder seu público. O público aceita a presença do boneco clássico, contrariamente a certos artistas. Aliás, engana-se quem imagina que o surgimento do teatro de bonecos com meios de expressão variados resultou do esgotamento do teatro de bonecos homogêneo.[...] Eles coexistem com o teatro de bonecos heterogêneo e os dois polarizam o interesse de diferentes artistas. O desenvolvimento das artes, a estilização plástica e gestual oferecem as condições de uma profunda transformação para o teatro de bonecos clássico. Não é, pois, surpreendente que este teatro tenha tido uma quantidade tão grande de adeptos. Por outro lado, o fato de que estes bonequeiros tenham se sentido ameaçados pela pressão dos modernos, era muito mais surpreendente!
\end{abstract}

No início da década de 1950 muitos bonequeiros não aceitavam esta presença do animador em cena, mas ao final da década alguns destes mesmos artistas já haviam mudado de idéia. Um exemplo disto é mencionado também por Jurkowski (2000) com relação a Hans Richard Purschke, que em 1953 escreveu um texto declarando-se contra a presença simultânea do boneco e animador em cena, alegando que a presença do animador dá ao espectador a possibilidade de perceber a verdadeira natureza inerte do boneco, rompendo o encantamento e a ilusão que estas figuras provocam no público. No entanto, no ano de 1958 Purschke demonstra aceitar a animação de bonecos à vista do público e publica em sua revista chamada "Perlicko-Perlacko", um texto de Tankred Dorst que defende e incentiva a desmistificação na animação de bonecos, exibindo ao espectador tudo aquilo que até então procurava-se ocultar, inclusive o animador (JURKOWSKI, 2000). 
Na década de 1960, a discussão a respeito da animação à vista não estava tão relacionada à presença ou não do animador, mas se dava predominantemente a respeito das motivações de colocá-lo em cena. Conforme discorre Jurkowski (2000, p.78),

\begin{abstract}
Os valores semânticos da representação foram implicitamente modificados e ninguém levantou questões sobre a contribuição artística da animação à vista. E de que ela pudesse mudar a expressão artística do boneco. Para muitos bonequeiros, constatar que existe uma diferença entre dois tipos de animação (à vista ou oculta) basta-lhes para adotar esse princípio como nova norma da modernidade e praticá-la.
\end{abstract}

E esta prática, de certo modo, exigiu dos bonequeiros um desenvolvimento mais aprimorado das suas técnicas teatrais. Numa linguagem que começava a se tornar heterogênea, não bastaria mais ter somente bonecos bem construídos. A interpretação do bonequeiro se destaca, estando ele visível ou não, e novas denominações passam a identificar estes artistas. Assim encontramos o ator-manipulador, ator-bonequeiro e ator- animador, como alguns exemplos de nomenclaturas que procuram associar o trabalho do ator ao trabalho do animador ${ }^{7}$.

Talvez o período de maior força na disseminação e desenvolvimento da animação à vista, aconteceu na década de 1970. A $\mathrm{UNIMA}^{8}$ tem uma participação importante neste processo, pois é com os congressos e festivais internacionais por ela promovidos, que artistas de vários países do mundo têm a possibilidade de refletir e discutir sobre esta linguagem. No espaço de tempo de aproximadamente duas décadas, o que em princípio poderia ser apenas um recurso cênico ou uma técnica, consolidou-se como uma linguagem com características próprias no Teatro de Animação.

\title{
Desenvolvimento e diversidade técnica
}

Com o desenvolvimento das linguagens no Teatro de Animação, especialmente na segunda metade do século XX, surgiram também novas possibilidades e desafios ao bonequeiro à vista do público. Segundo Michael Meschke (1985, p.32),

\footnotetext{
${ }^{7}$ Uso o termo Animador em sua forma mais abrangente, identificando o artista que anima (dá ânima, alma) a bonecos antropomorfos, zoomorfos, amorfos, máscaras, silhuetas, objetos etc.

${ }^{8}$ União Internacional da Marionete - criada em 1929, na cidade de Praga / República Tcheca.
} 
Pode-se afirmar que no mesmo instante em que o titeriteiro aparece, aparece também ante os intérpretes uma série de possibilidades de escolha que vão desde a discrição máxima - como se o titeriteiro não estivesse ali - até o puro exibicionismo quando o titeriteiro se apodera do interesse do espectador em prejuízo do boneco. Em algum momento entre estes extremos, a presença do titeriteiro começa a ser um fim em simesmo.

Podemos destacar entre as diversas modalidades de animação à vista, as que seguem:

- O animador visível, porém neutro na cena: Neste modo, o bonequeiro não possui uma função ativa como personagem. Ele pode ser metaforicamente uma "sombra" do boneco, como ocorre no Bunraku. O bonequeiro é um corpo dissimulado ao fundo do espaço cênico, ou simplesmente alguém que comanda os movimentos do boneco. Sua movimentação e presença não ganham destaque, podendo assim, ser aceito em convenção com o público como algo que não existe. Segundo Valmor Beltrame (2003, p.48)

\footnotetext{
Trata-se de trabalhar com a noção de consciência de estar em cena, o que exige movimentos comedidos, discretos, elegantes, suficientes para que se remeta o foco das atenções ao boneco presente na cena e não ao seu animador. Quando os gestos do ator-titeriteiro e sua presença são mais eloqüentes que a presença do boneco, cria-se um duplo foco que desvaloriza acena.
}

- O animador à vista do público como parte integrante do cenário: Nesta modalidade o bonequeiro mantém as características do animador visível, porém neutro na cena, diferenciando-se pelo fato de que seu corpo e figurino compõem o espaço metafórico de representação, o cenário. Seu figurino colabora para criar a noção de lugar ou ambiente, o que minimiza a presença do animador e ele não se configura como personagem da narrativa, ou seja, ele não interfere no desenvolvimento das ações dos personagens enquanto uma presença ativa em cena. Isto o justifica como um elemento de dupla função, pois além de animar o boneco ele situa o espaço cênico.

- O animador assume seu corpo em cena sem representar um personagem: O animador atua não representando personagens enquanto anima o boneco. Neste modo, o bonequeiro tem a liberdade de relacionar-se diretamente com o personagem-objeto, criando contrapontos entre o ser vivo e a matéria inerte que aparenta ter vida. Freqüentemente acontece deste animador atuante explorar as relações de dependência e 
independência entre personagem-objeto e animador, como afirma Meschke (1985, p. 35)

Essa missão pode consistir em mostrar uma relação de contraponto com o títere como manifestar a total dependência do títere ao titeriteiro: sem este não há vida!. Ou ao contrário. Pode intensificar-se até resultar em uma competição entre títere e manipulador e em conflitos entre eles. Mas o manipulador segue sendo manipulador e sua participação no que acontece é como tal.

- O animador é o duplo do personagem-objeto: Desta forma o animador está em situação de interpretação em paridade com o boneco. Sua relação com o boneco geralmente não é de disputa, mas de complementaridade e formam o duplo da personagem. Eles atuam muitas vezes em diferentes planos ficcionais. Desta relação podem nascer diversos conflitos dramáticos, inclusive relativos à autonomia do boneco. Ao discorrer sobre a dramaturgia nesta possibilidade do animador como um duplo, Felisberto Sabino da Costa (2000, p.45) escreve:

No que diz respeito ao signo interposto entre o ator-manipulador e público, utilizando-se tamanhos diferenciados de personagens e objetos, os efeitos cênicos daí decorrentes proporcionam conflitos dramáticos visuais. Ator e boneco, ao representarem o mesmo personagem, criam inúmeras possibilidades fantasmáticas conflituais.

Michael Meschke (1985, p.33) denomina esta modalidade como "Bonequeiro como Contraparte" e Rafael Curci (2000, p.124) denomina de "Co-presença" ao escrever:

\begin{abstract}
Mediante o modo de co-presença a identidade do personagem se completa de alguma maneira com a voz e os gestos residuais - inclusive os faciais, por menores que sejam - que o titeriteiro confere ao títere (muitas vezes sem querer) durante o ato interpretativo. Desde o ponto de vista físico são dois corpos que, de alguma maneira, têm a intenção de fusionar-se para plasmar uma identidade cênica, a do personagem. Mas por mais cuidado que tenha o manipulador ao mostrar-se com seus títeres frente ao público, sua co-presença será sempre aceita como dizemos, por pura convenção [...]. (tradução minha do trecho. Grifos do autor).
\end{abstract}

- O animador representa simultaneamente dois personagens - o vivido pelo boneco

e o representado por ele: A realização deste modo de atuação torna-se mais complexa, uma vez que o animador tem de interpretar dois personagens distintos quase simultaneamente, exigindo a construção e o desenvolvimento de todos os aspectos 
destes personagens no plano ficcional em que se encontram. Neste caso, o animador também necessita ter um conhecimento apurado não só das particularidades da arte da animação, mas também das particularidades da interpretação do chamado "teatro de atores". Compreende-se que especialmente nesta modalidade, nem todo ator é um bonequeiro, mas todo bonequeiro necessita ser um ator. Segundo Michael Meschke (1985, p.35):

Embora ambas profissões estão orientadas ao teatro, o ponto de partida e os métodos de trabalho são completamente distintos para o titeriteiro e para o ator. Aquele que o compreende, respeita ambas manifestações artísticas. Uma boa representação de títeres exige concentração total. Nela há determinados momentos de uma técnica e uma precisão física que para o ator são desconhecidos. As exigências a que está submetido o titeriteiro são suficientemente grandes para ocupar-lhe inteiramente. E o mesmo se pode dizer a respeito do ator, partindo de outro ponto de vista.

Independentemente do modo como se apresente o animador, é importante levar em consideração o fato de que tudo o que está em cena representa algo e tem alguma função. A animação à vista do público traz grandes possibilidades expressivas que podem ser também traiçoeiras, pois facilmente o artista se perde no exibicionismo deixando de cumprir a sua função fundamental, que é a de animar o boneco.

Estes são apontamentos que abrem a discussão sobre a animação à vista do público. $\mathrm{A}$ atuação do animador visível ao espectador gera inúmeras reflexões e encaminha para a necessidade de pesquisas, pois é uma linguagem que ainda se encontra em pleno desenvolvimento e pode ajudar a esclarecer as tendências de nossa arte contemporânea.

\section{REFERÊNCIAS}

BELTRAME, Valmor. O Trabalho do Ator-Bonequeiro. Revista NUPEART, Florianópolis, SC, v.2, n.2, p. 33-52, set. 2003.

COSTA, Felisberto Sabino da. A Poética do Ser e Não Ser: Procedimentos dramatúrgicos do teatro de animação. Tese de Doutorado defendida no Programa de Pósgraduação da ECA/USP. São Paulo, 2000.

CURCI, Rafael. Dialéctica del Titiritero em Escena: Uma propuesta metodológica para la actuación con títeres. Buenos Aires: Colihue, 2007. 
JURKOWSKI, Henryk. Métamorphoses: La Marionnette au XX Siécle. Tradução: Eliane Lisboa. Charleville-Mézières: Éditions Institut International de la Marionnette, 2000. No Prelo.

KUSANO, Darci. Os teatros Bunraku e Kabuki: Uma visada barroca. São Paulo: Perspectiva, 1993.

MESCHKE, Michael. ¡Una estética para el teatro de títeres! Bizkaia: Gráficas Arratia, 1985.

\section{REFERENNCIAS COMPLEMENTARES}

AMARAL, Ana Maria. O ator e seus duplos: máscaras, bonecos, objetos. São Paulo: Editora SENAC São Paulo, 2002.

AMORÓS, Pilar; PARICIO, Paco. Títeres y Titiriteros: El lenguaje de los Títeres. $2^{\mathrm{a}}$ ed. Binéfar: Pirineum editorial, 2005.

GIROUX, Sakae M.; SUZUKI, Tae. Bunraku: Um teatro de bonecos. São Paulo: Perspectiva, 1991. 